\title{
New Technology and Experimental Study on Snow-Melting Heated Pavement System in Tunnel Portal
}

\author{
Jinxing Lai, ${ }^{1,2}$ Junling Qiu, ${ }^{2}$ Jianxun Chen, ${ }^{1,2}$ Haobo Fan, ${ }^{2}$ and Ke Wang ${ }^{2}$ \\ ${ }^{1}$ Shaanxi Provincial Major Laboratory for Highway Bridge \& Tunnel, Chang'an University, Xian 710064, China \\ ${ }^{2}$ School of Highway, Chang'an University, Xian 710064, China \\ Correspondence should be addressed to Jinxing Lai; 373159626@qq.com and Junling Qiu; 870133597@qq.com
}

Received 30 April 2015; Accepted 29 June 2015

Academic Editor: João M. P. Q. Delgado

Copyright (c) 2015 Jinxing Lai et al. This is an open access article distributed under the Creative Commons Attribution License, which permits unrestricted use, distribution, and reproduction in any medium, provided the original work is properly cited.

\begin{abstract}
In recent years, with the rapid growth of economy and sharp rise of motor vehicles in China, the pavement skid resistance in tunnel portals has become increasingly important in cold region. However, the deicing salt, snow removal with machine, and other antiskid measures adopted by highway maintenance division have many limitations. To improve the treatment effect, we proposed a new snow-melting approach employing electric heat tracing, in which heating cables are installed in the structural layer of road. Through the field experiment, laboratory experiment, and numerical investigation, structure type, heating power, and preheating time of the flexible pavement heating system in tunnel portal were systematically analyzed, and advantages of electric heat tracing technology in improving the pavement skid resistance in tunnel portal were also presented. Therefore, such new technology, which offers new snow-melting methods for tunnel portal, bridge, mountainous area, and large longitudinal slope in cold region, has promising prospect for extensive application.
\end{abstract}

\section{Introduction}

With the rapid development of highway construction in China, more and more highways have been built in the cold region with high latitude and high altitude. Heavy snows in the cold region cause the soil freezing and snow cover on the pavement in tunnel portals and greatly reduce the friction coefficient of pavement, which often result in motor vehicle accidents and endanger the drivers and passengers. In north China, the winter usually lasts for 56 months and even for 8 months in Heilongjiang Province, Xinjiang Uygur Autonomous Region, and Inner Mongolia Autonomous Region. Every year, heavy snows will occur in such regions for several times. Moreover, heavy snows will cause severe adverse impact on people's production, transportation, and traffic safety [1], as shown in Figure 1. According to the statistics, the occurrence of traffic accident in the snow and ice road in winter is 4-5 times of that in other seasons, which may result in the annual economic loss of tens of millions of dollars. Therefore, more and more research has focus on the pavement skid resistance in tunnel portal [2-5]. In order to ensure the smooth traffic in tunnel portal and guarantee the normal operation of highway, it is necessary to take effective measures to eliminate the snow and ice on the pavement in tunnel portal. Considering the traffic safety, energy consumption, economic benefit, environmental protection, and other related factors, it is of great practical significance to change the conventional concept and method for snow-melting and skid resistance of the pavement $[6-8]$.

Losses and damage caused by heavy snow are steadily increasing worldwide. Severe heavy snow paralyses national logistics systems, limiting snow removal efforts. To overcome this, many snow-melting systems have been developed; however, in practice, their application is restricted, due to economic reasons, environmental contamination, and problems and cost associated with construction technology. With respect to the treatment of the snow and ice on the pavement, researchers have conducted many studies and proposed several methods for snow-melting and skid resistance of the pavement [9-13], as shown in Figure 2. Currently, there are two major methods for melting ice and snow: snow removal 


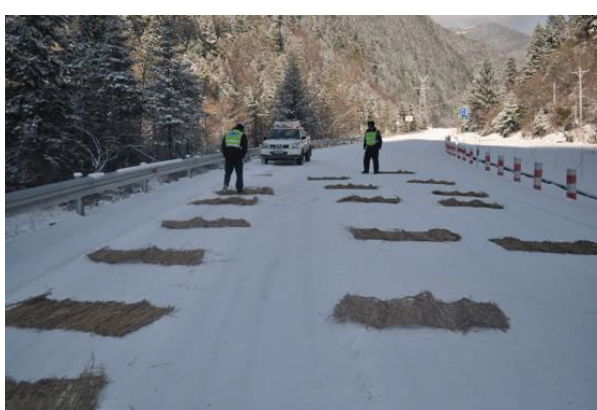

(a)

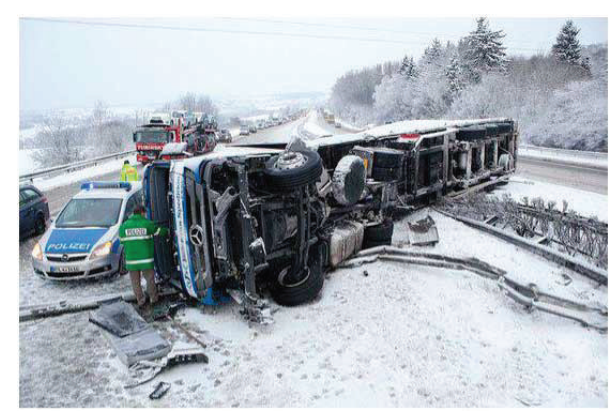

(b)

FIGURE 1: Influence of the snow and ice road on traffic safety.

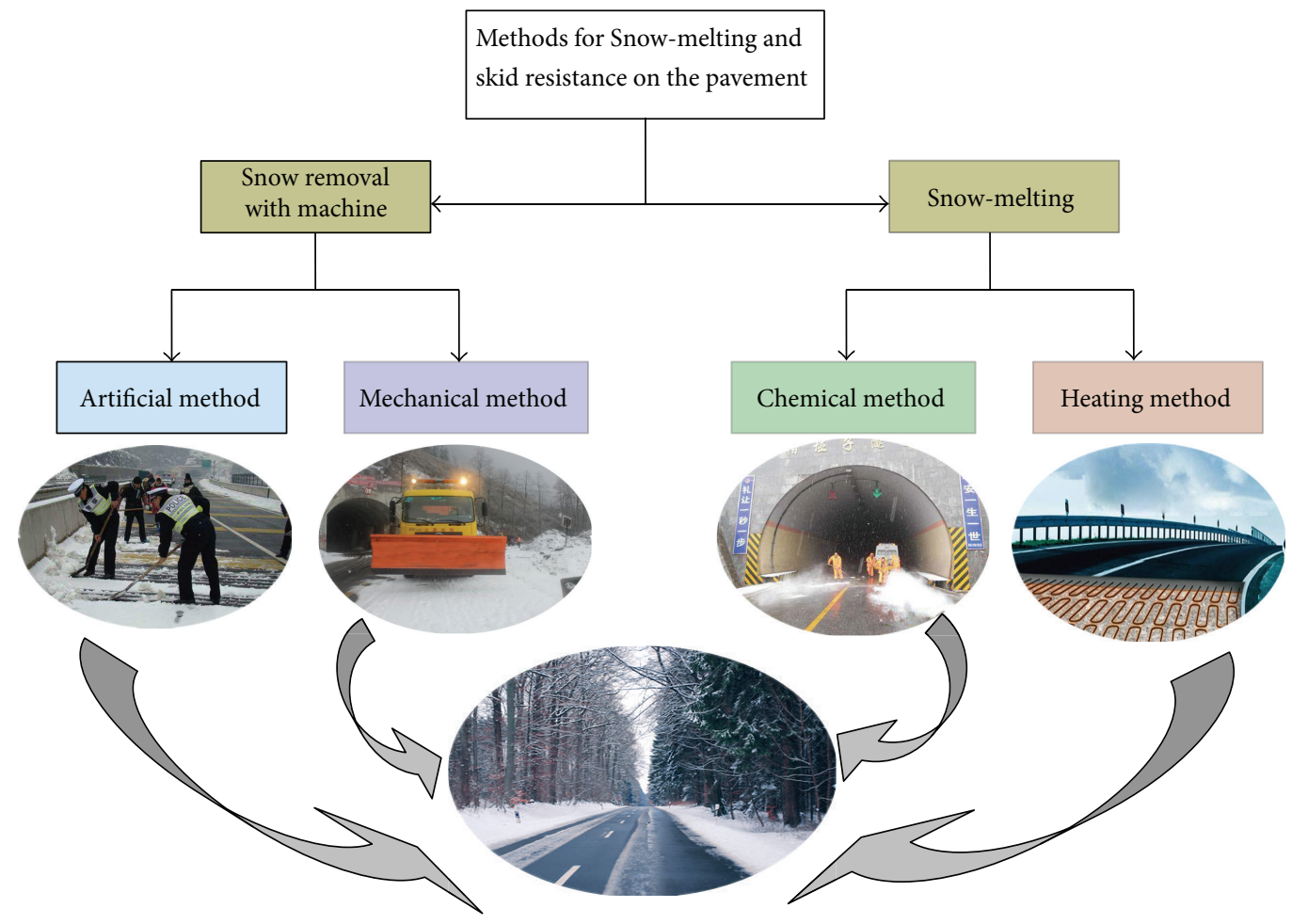

FIGURE 2: Methods for snow-melting and skid resistance of the pavement.

with machine and snow-melting. With high efficiency, snowremoving machines are applicable for removing large area of snow and ice on pavement. However, considering the larger cohesive force between ice and pavement induced by the lower temperature, the snow-removing machine alone cannot achieve satisfactory snow removal effect and cannot thoroughly remove the ice cover on pavement. Generally, the snow-melting method can be divided into two kinds, namely, chemical method and heating method. The heating method employing the heat pump, infrared lamp, heating wire, or hydrothermal fluid has a promising prospect of application [14]. The chemical method, employing deicing chemicals $\left(\mathrm{NaCl}\right.$ or $\left.\mathrm{CaCl}_{2}\right)$ to melt the snow and ice, has been extensively applied with the advantages of extensive source of materials, low price, and excellent snow and ice melting effect [15-18]. The deicing chemicals used for melting ice and snow on pavement, however, have caused many negative effects, which may include the corrosion of steel reinforcing bars, pavement abrasion, and environmental pollution [1922]. In many countries where the chemical reagents are widely used to remove snow and ice, many roads and bridges have to be repaired at huge cost, which result in enormous economic loss [23-27]. Therefore, in order to improve the skid resistance of pavement in cold-region tunnel portal and guarantee the safe operation of highway, it is of great significance to develop the new snow-melting and antiskid technology.

In previous decades, America, England, Canada, and some other countries have conducted experimental researches on the snow-melting heated pavement system [28-30]. In America, Yehia and Tuan [14, 28] summarized the snow-melting measures (i.e., chemical method, heat 


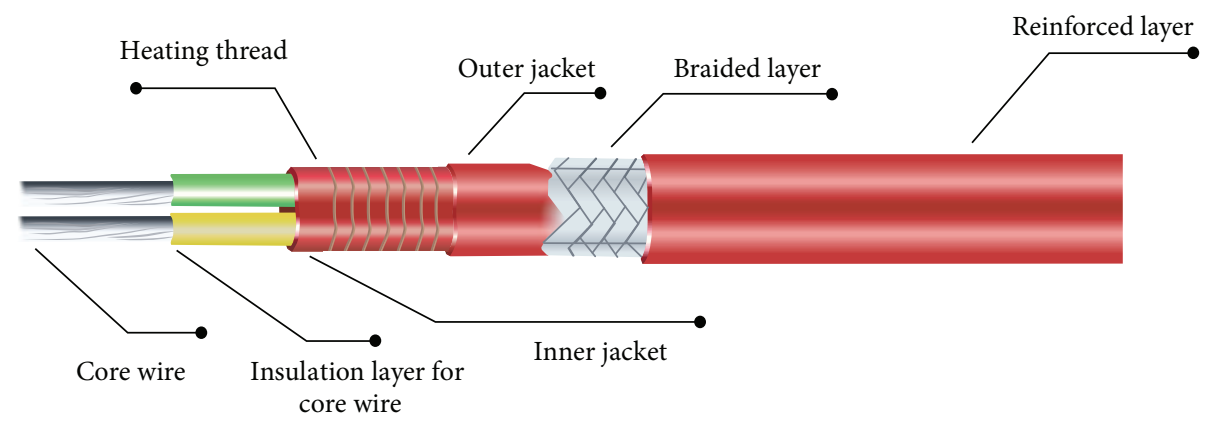

FIGURE 3: Heating cable composition.

pump method, infrared lamp irradiation method, heating wire method, and hydrothermal method) of pavement. The conductive concrete was proposed to melt ice and snow on road surface, and the experimental research on the snow-melting measures for bridge and concrete pavement was performed. In 2001, Sun [31], from Guangzhou Electrical Power Design Institute, China, studied the application of conductive concrete in the grounding grid of substation, and excellent research results were obtained. In 2002, Tang et al. [32], from Wuhan University of Technology, China, analyzed the influence of the heating layer of conductive concrete on the pavement skid resistance, and the research results show that the heating layer covered by conductive concrete can realize better snow-melting and deicing effect.

The electric heat tracing system commences as a new method for the pavement snow-melting in tunnel portal, bridge, mountainous area, and large longitudinal slope in cold region, which can also serve as references for effective design and construction of similar projects in urban roads. Moreover, with the advantages of excellent performance in environmental protection, renewable energy source, simple structure, convenient usage, and low manufacturing cost, the electric heating tracing technology enjoys promising prospect for extensive application.

\section{Electric Heat Tracing System}

2.1. Working Principle of the System. Electric heat tracing system, using wire as heating medium, transforms electric energy into thermal energy by electrifying the heating cable and then transfers the thermal energy to pavement, which is the radiant heating. With additional protection of the outer wall of heat insulation material, the significant effect of heat insulation and snow-melting can be received [33]. The heating cable, as shown in Figure 3, is mainly composed of several elements, which are heating thread, insulation layer, metal shielding layer, waterproof and anticorrosion layer, and so forth. The self-limiting temperature heating belt, which is generally used in the current, has the electrical resistivity with high positive temperature coefficient (PTC). The PTC material will transform electric energy into thermal energy; that is, the temperature of the heating unit is rising, when in an energized state. Besides, the electrical resistivity increases gradually with the effect of PTC.
With the advantages of high thermal efficiency, little impact on structure, excellent effect, excellent performance in energy conservation, simple design, convenient installation, zero pollution, long service life, and remote-automatic control, the electric heat tracing system has been successfully applied in architectural engineering, oil engineering, chemical engineering, mechanical engineering, and so on. In the early 1990s, the electric heat tracing technology was first introduced into China. Later, along with the advance of material technology and electronic technology, this technology was experiencing a very rapid growth in various fields of engineering construction [34].

2.2. Application of the System in Pavement Engineering. Heating cables are usually laid in zigzag pattern as the following process: firstly, the coarse gravel asphalt concrete or other similar materials are laid in the structural layer of pavement; then, the heating cables with required power are laid according to related technical requirements; finally, the fine gravel asphalt concrete is laid as the surface layer of pavement, as shown in Figure 4. The electric heat tracing system, which is employed for snow-melting and deicing, is designed with the intermittent operation model. Ramsey and Kilkis [35, 36] had recommended that the input power of electric heating cable system be $250-400 \mathrm{~W} / \mathrm{m}^{2}$ for the asphalt pavement. The heating cables generate thermal energy gradually, then the thermal energy is transferred to the snow cover through the asphalt concrete, and finally the snow will be melted after absorbing sufficient heat.

The snow-melting heated pavement system comprises the heating system and control system, as shown in Figure 5. The composite pavement $(4 \mathrm{~cm}$ fine gravel asphalt concrete + $5 \mathrm{~cm}$ medium gravel asphalt concrete $+22 \mathrm{~cm}$ cement concrete), before installing the electric heat tracing system, is often required to be designed according to the internal structure of pavement and working features of heating cable. Firstly, $2 \mathrm{~cm}$ (width) $\times 2 \mathrm{~cm}$ (depth) grooves are carved on the cement concrete surface of the composite pavement. Then, heating cables are installed inside the grooves and fixed with clamps and cement nails, as shown in Figure 6. Note that the redundant length shall be reserved for the heating cable, so as to avoid the higher stress on heating cable when the pavement deformation is large. Finally, temperature-controlled cables 


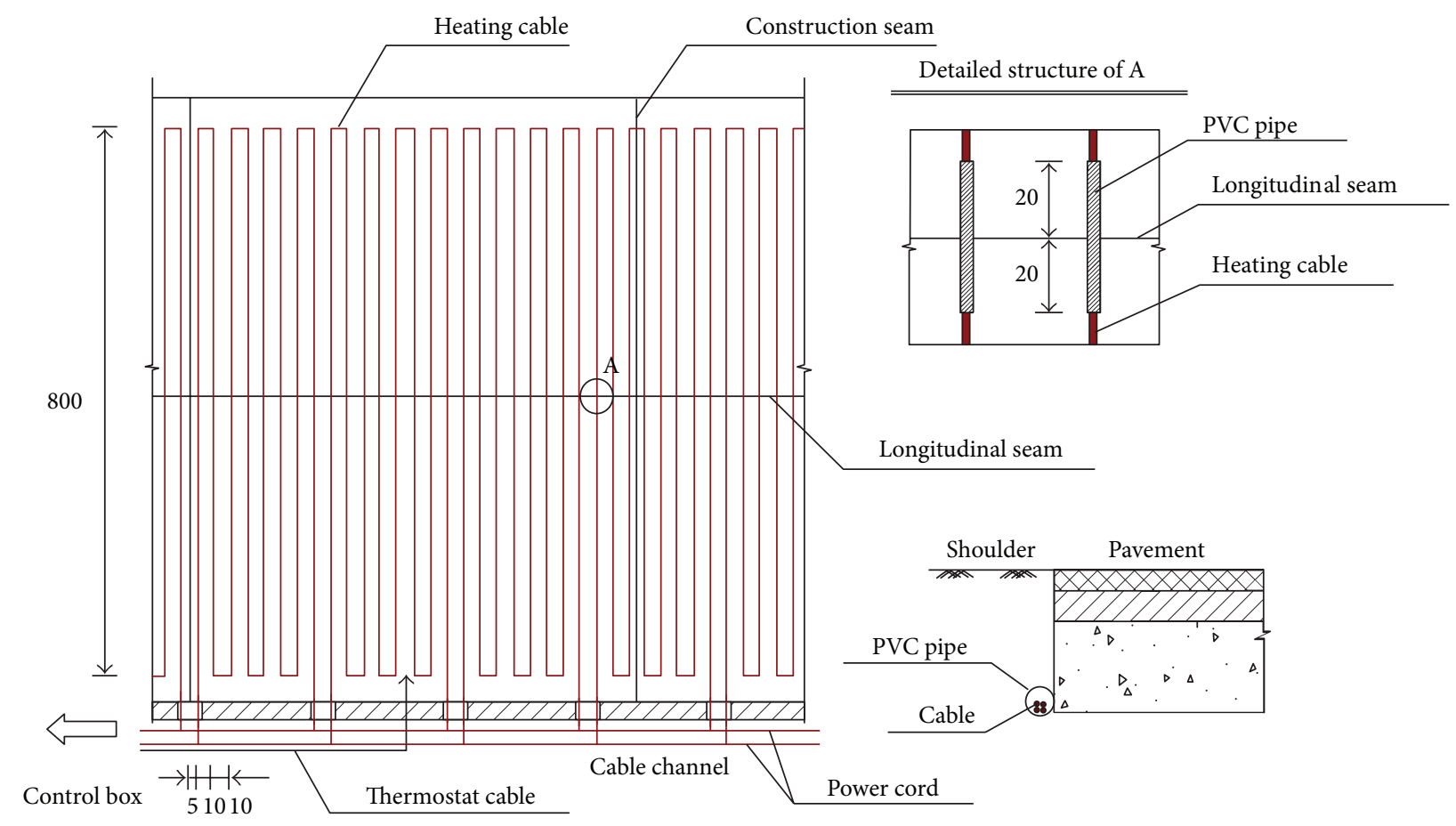

FIGURE 4: Working principle of the electric heat tracing system.
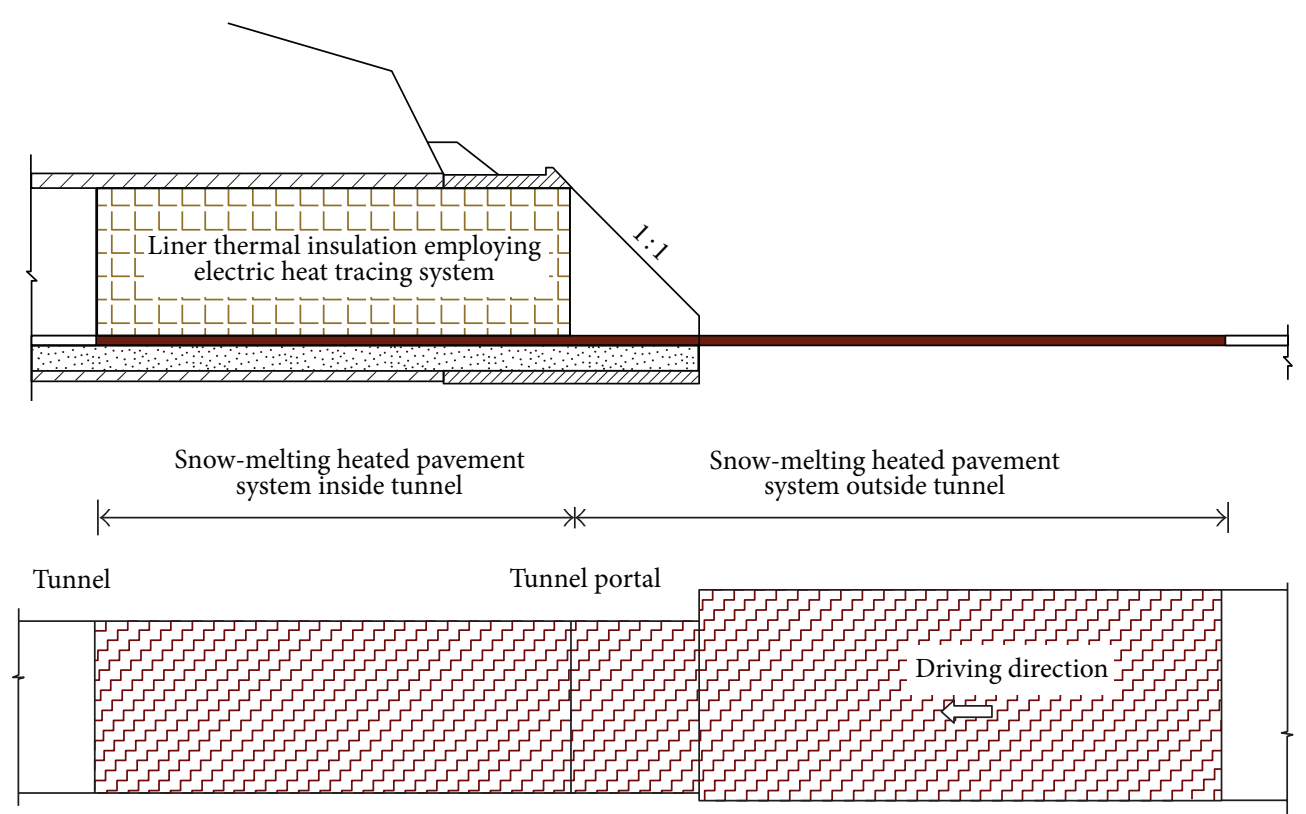

FIgURE 5: The snow-melting heated pavement system.

are installed as the same procedure. Once the cable laying is completed, it is required to start the laying of asphalt concrete layer. Moreover, the heating cable and temperaturecontrolled cable are led out from the brim of pavement slab, which are placed in the cable duct and connected with the control circuit after crossing the gutter. Generally, the remoteautomatic control of heating cables can be realized through the control system.

\section{Experimental Study on Snow-Melting Heated Pavement System in Tunnel Portal}

In this paper, comprehensive comparison and analysis were conducted through field experiment, laboratory experiment, and numerical investigation, and systematic analysis was also performed on the practicality of pavement snow-melting effect for the electric heat tracing system in tunnel portal, 


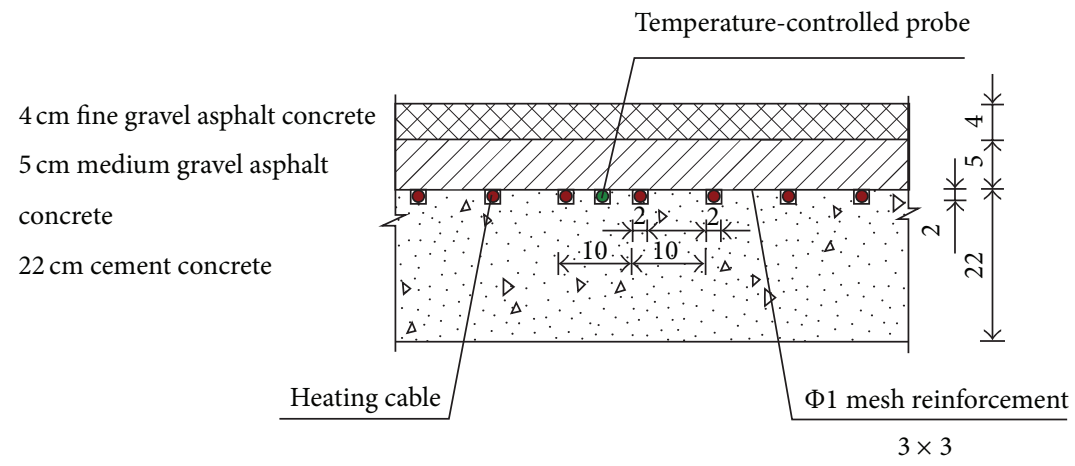

FIGURE 6: Schematic diagram of the pavement with electric heat tracing system.

which can provide necessary technical support for the design, construction, and operation of electric heat tracing system.

3.1. Field Experiment. The field experiment was conducted in Dongnanli Tunnel in Tumen City, Jilin Province, China. Dongnanli Tunnel, as shown in Figure 7, is $1252 \mathrm{~m}$ in length, with the maximum depth of $101 \mathrm{~m}$. The tunnel is located at seasonal cold region, belonging to the denudation of mountain topography. In this area, the first snow comes in the mid October, and the last snow comes in April of next year. The winters are bitterly cold and long while the summers are cool. By reference to the meteorological history data for many years, the extremely high temperature is $37.6^{\circ} \mathrm{C}$, the extremely low temperature is $-27.2^{\circ} \mathrm{C}$, the maximum freeze depth is about $1.81 \mathrm{~m}$, and the maximum snow depth is $48 \mathrm{~cm}$.

The longitudinal length of the pavement with electric heat tracing system was determined by the air temperature, vehicle emergency braking distance, and "snow scarp" effect. In the field experiment, the length of the pavement with electric heat tracing system inside the tunnel was $50 \mathrm{~m}$, and that outside the tunnel was also $50 \mathrm{~m}$. Heating cables were installed according to the related design. The on-site construction is shown in Figure 8. After completing the laying of heating cables, the testing personnel, according to the forecast of snowfall, conducted the field experiment in late February 2011. The testing personnel changed the control mode of single-circuit switch and double-circuit switch to monitor the heating effect. And the main working indexes of electric heat tracing system were collected accordingly. The air temperature at the test site is shown in Figure 9. The results of field experiment show that the electric heat tracing system can realize excellent snow-melting and antiskid effect, which conserves a lot of manpower and material resource.

The surface temperature of heating cable reached 40$60^{\circ} \mathrm{C}$ during the field experiment; however, the maximum surface temperature should not be above $60^{\circ} \mathrm{C}$ for avoiding the softening of asphalt. After the snow, the heating test was conducted at 8:00 a.m. and lasted for $10 \mathrm{~h}$. The air temperature reached $-11.3^{\circ} \mathrm{C}$ and the pavement temperature reached $-8.3^{\circ} \mathrm{C}$. Table 1 gives the pavement temperature after the electric heat tracing system working for $3 \mathrm{~h}, 5 \mathrm{~h}, 8 \mathrm{~h}$, and $10 \mathrm{~h}$ with the $300 \mathrm{~W}$ single-circuit heating cable and $600 \mathrm{~W}$

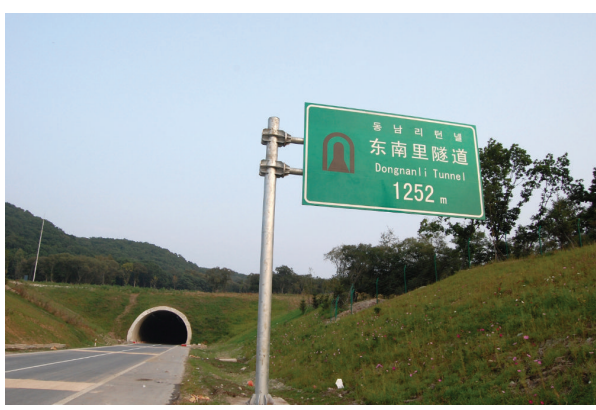

Figure 7: Dongnanli Tunnel.

TABLE 1: Temperature monitored in field experiment.

\begin{tabular}{lccccc}
\hline Heating time & 0 & $3 \mathrm{~h}$ & $5 \mathrm{~h}$ & $8 \mathrm{~h}$ & $10 \mathrm{~h}$ \\
\hline Air temperature $\left({ }^{\circ} \mathrm{C}\right)$ & -11.3 & -8.9 & -7 & -7.9 & -9.5 \\
\hline $\begin{array}{l}\text { Pavement temperature with } \\
\text { single-circuit heating cable }\left({ }^{\circ} \mathrm{C}\right)\end{array}$ & -8.3 & -2.4 & 0.8 & 1.96 & 3.4 \\
\hline $\begin{array}{l}\text { Pavement temperature with } \\
\text { double-circuit heating cable }\left({ }^{\circ} \mathrm{C}\right)\end{array}$ & - & 0.6 & 2.3 & 3.2 & 3.8 \\
\hline
\end{tabular}

double-circuit heating cable. The temperature testing at the site is shown in Figure 10.

Before the snow, the pavement temperature can reach 2$3^{\circ} \mathrm{C}$ by the electric heat tracing system. Once the snow started, the pavement temperature is sufficient to melt the snow and ice, which can ensure the expected snow-melting effect. More specifically, in order to achieve the satisfactory antiskid effect for pavement, it is better to preheat the pavement to $2-3^{\circ} \mathrm{C}$ within 4-6 h.

Additionally, in order to study the effect of increased temperature on the mechanical properties of the pavement, the verification tests on the high temperature stability and fatigue performance of the asphalt pavement were conducted by $\mathrm{Xu}$ [37]. Through the fatigue test and rutting test, it can be seen that the installation of electric heat tracing system has relatively little influence on the mechanical properties of the pavement. In addition, the asphalt concrete with electric heat tracing system has longer fatigue life and better parallelism. 


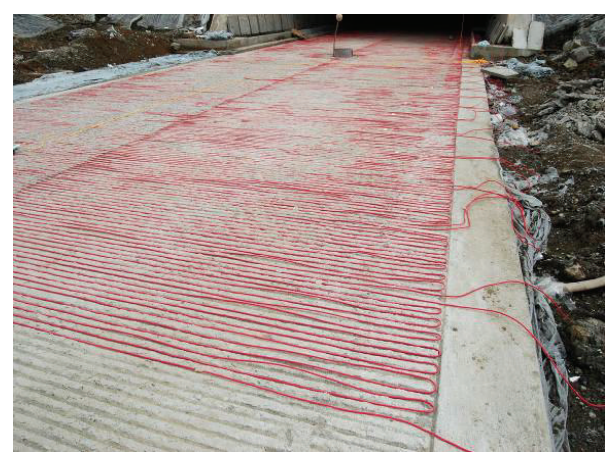

(a)

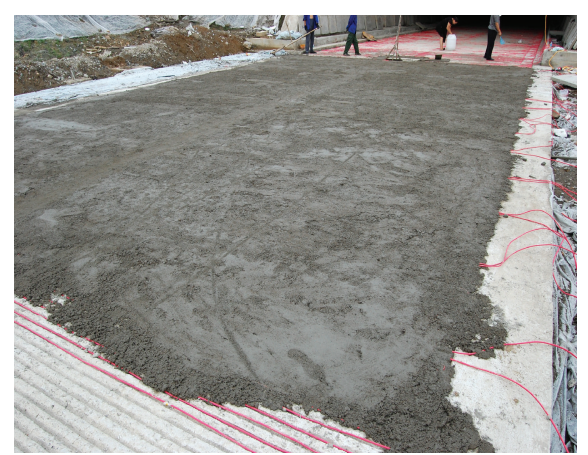

(b)

FIGURE 8: On-site construction of electric heat tracing system.

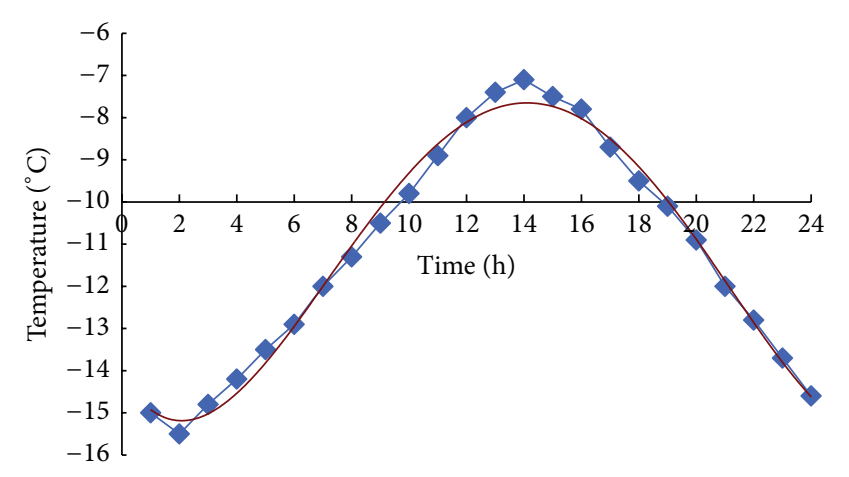

Figure 9: Air temperature curve at the test site.

3.2. Laboratory Experiment. It is difficult to conduct the field experiment systematically because the temperature at the site changes irregularly and has large discreteness, but, comparatively speaking, the laboratory experiment can be conducted under optimal temperature condition [38]. And the relationship among the pavement temperature field, air temperature, and environmental factors can be analyzed under the specified temperature condition. Additionally, the installation technology and installation mode of electric heat tracing system can also be optimized.

In the laboratory experiment, the cement concrete layer was laid according to the structural requirements detailed in Table 2 . The heating cable used in laboratory experiment had the linear heating power of $17 \mathrm{~W} / \mathrm{m}$, input power of $252 \mathrm{~W}$, and the maximum surface temperature of $60^{\circ} \mathrm{C}$. When the laying of heating cable was finished as related requirements, a layer of steel wire mesh with the diameter of $\Phi 1 \mathrm{~mm}$, length and width of $3 \times 3 \mathrm{~cm}$, was laid upon the heating cable, so as to transfer the thermal energy. Then, the asphalt concrete surface layer was laid according to the structural requirements (see Figure 11). In order to obtain real-time data about the temperature change on road surface, temperature elements were installed on the specimen surface. Typically, three temperature measuring points, which were measuring point $\mathrm{A}$, measuring point $\mathrm{B}$, and measuring point $\mathrm{C}$, were placed, as shown in Figure 12. Then, considering the symmetry and periodicity of the system, it was enough to analyze the
TABLE 2: Asphalt concrete pavement structure.

\begin{tabular}{lcl}
\hline Name & Thickness $(\mathrm{cm})$ & Material \\
\hline Surface layer & 4 & Fine gravel asphalt concrete \\
Middle layer & 5 & Medium gravel asphalt concrete \\
Base layer & 22 & Cement concrete \\
\hline
\end{tabular}

temperature of the specimen surface in an all-round way with the three measuring points. In the laboratory experiment, the intelligent multiloop measuring and control instrument was employed to monitor the temperature for every $0.5 \mathrm{~h}$. In the first test, without snow, the temperature of specimen surface reached $2.43^{\circ} \mathrm{C}$, and the surface temperature of heating cable reached $17.22^{\circ} \mathrm{C}$ after the system worked 5 hours. In the second test, the snow on specimen surface began to melt after the system worked 4 hours, and all the snow was melted after the system worked 5.5 hours. In the third test, taking into account the air temperature of $-10^{\circ} \mathrm{C}$, the heating time was increased. The temperature of specimen surface reached $3.11^{\circ} \mathrm{C}$, and the surface temperature of heating cable reached $22.69^{\circ} \mathrm{C}$ after the system worked 10 hours. In the fourth test, the snow on specimen surface began to melt after the system worked 9 hours, and all the snow was melted after the system worked 11 hours.

Through the regression analysis of test results, the temperature change of measuring point $\mathrm{A}$ on the specimen surface with the air temperature of $-5^{\circ} \mathrm{C}$ and $-10^{\circ} \mathrm{C}$ (Figures 13 and 14) was as follows: in the initial period of experiment, the temperature of specimen surface rose quickly, which was similar to parabola. With the increase of the heating time, the temperature of the structural layer began to rise, the electrical resistivity of heating cable increased, and the calorific value of heating cable was reduced accordingly. In this period, the rate of temperature increase became slower gradually, the temperature field became stable, and the temperature curve became smooth and slow. Moreover, from the test results, it could be seen that the heating time for the stable status of temperature field with the air temperature of $-10^{\circ} \mathrm{C}$ was approximately two times that with the air temperature of $-5^{\circ} \mathrm{C}$. In summary, the electric heat tracing system had excellent snow and ice melting effect; however, its heating 


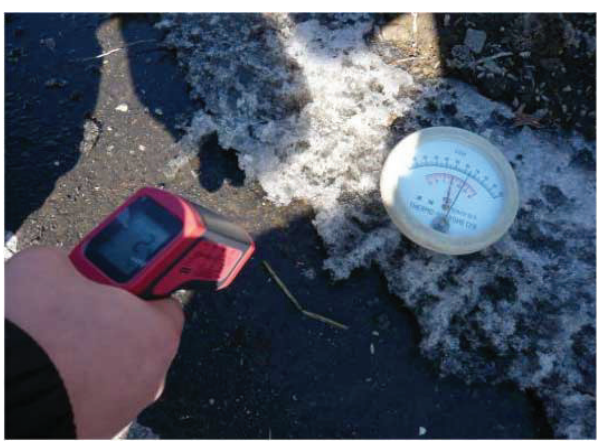

(a)

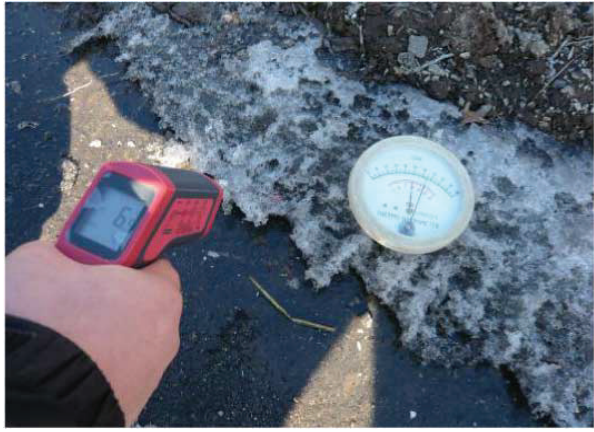

(b)

Figure 10: Temperature testing of the pavement outside the tunnel.

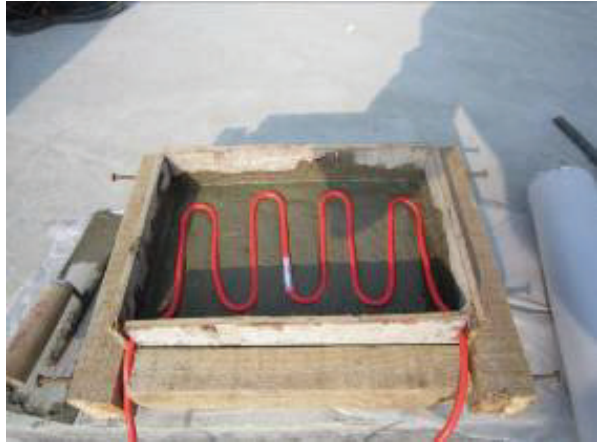

(a)

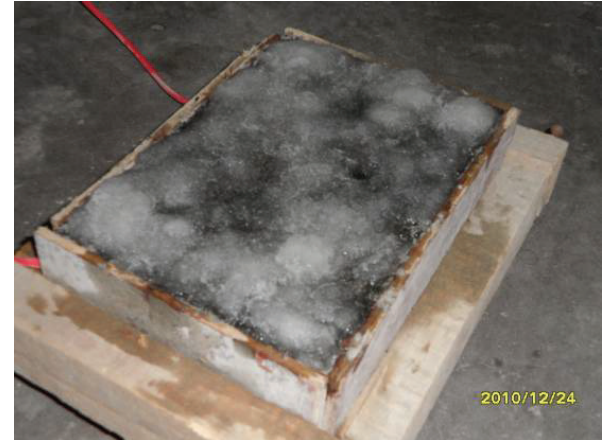

(b)

FIGURE 11: Laying of heating cable in the laboratory experiment.

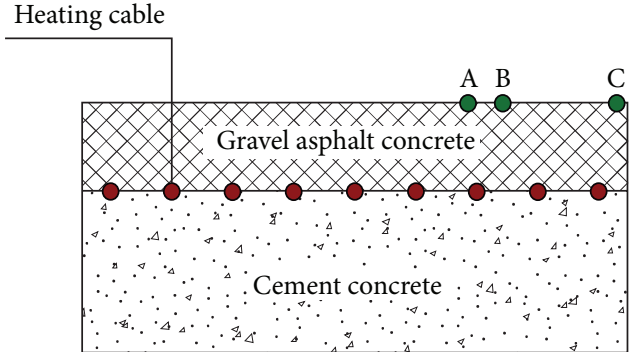

FIGURE 12: Distribution of temperature measuring points on the pavement.

power and heating time were necessary to be controlled and computed.

3.3. Numerical Investigation. Based on the finite element method, the basic laws among several key parameters that affect the snow-melting heated pavement system can be systematically studied, and characteristics of temperature distribution can also be summarized. In the numerical investigation, the snow-melting heated pavement system was regarded as the heat conduction on two-dimensional plane. Through the finite element software ANSYS, working stages of the system can be simulated, in which the PLANE 55 element was applied for computation [39]. Specifically,

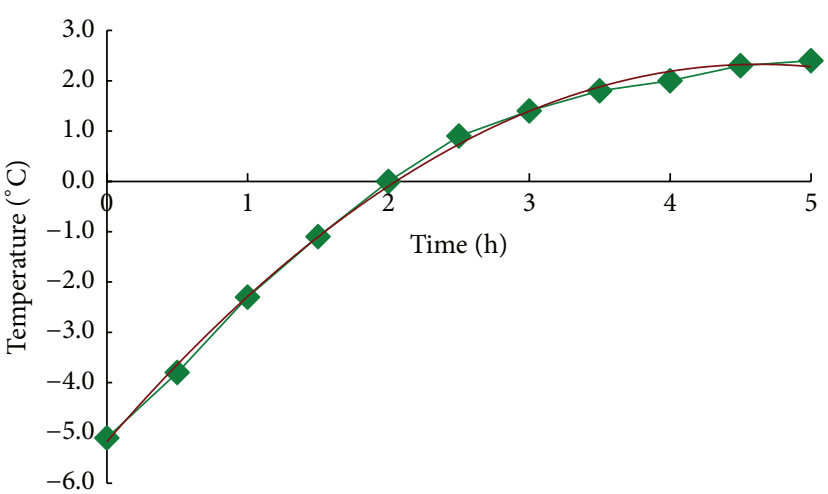

FIgURE 13: Temperature curve of the specimen surface with air temperature of $-5^{\circ} \mathrm{C}$.

the internal structure, heating power, external temperature, thermophysical properties of materials, and other physical parameters were obtained from field experiment and laboratory experiment, as shown in Table 3.

Considering the different properties materials in pavement structure, the pavement structure was divided into three different parts during establishing the finite element model, and such three different parts were bonded together by Boolean operation. Nonuniform mesh generation was performed in the model, and refined mesh was applied around 
Advances in Materials Science and Engineering

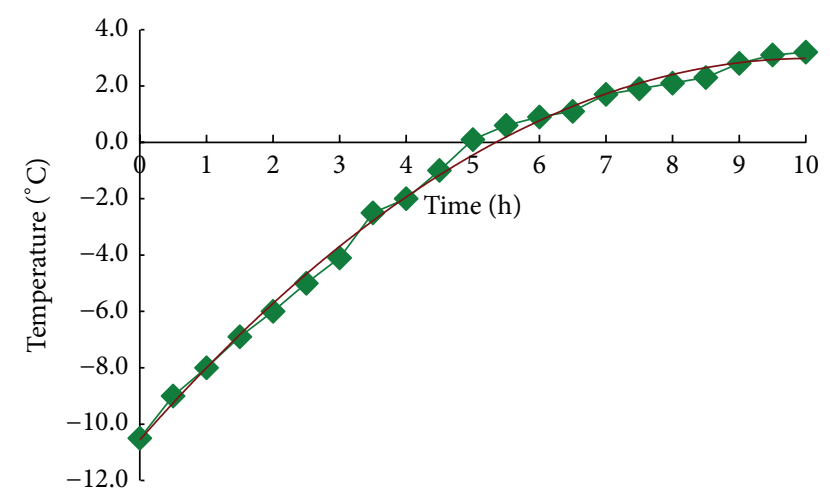

Figure 14: Temperature curve of the specimen surface with air temperature of $-10^{\circ} \mathrm{C}$.

TABle 3: Physical parameters of the pavement material.

\begin{tabular}{lccc}
\hline Material property & $\begin{array}{c}\text { Thermal } \\
\text { conductivity } \\
\left(\mathrm{J} /\left(\mathrm{M}^{\circ} \mathrm{C}\right)\right)\end{array}$ & $\begin{array}{c}\text { Heat capacity } \\
\left(\mathrm{J} /\left(\mathrm{kg}^{\circ} \mathrm{C}\right)\right)\end{array}$ & $\begin{array}{c}\text { Density } \\
\left(\mathrm{kg} / \mathrm{m}^{3}\right)\end{array}$ \\
\hline $\begin{array}{l}\text { Gravel asphalt } \\
\text { concrete }\end{array}$ & 1.3 & 920 & 2600 \\
$\begin{array}{l}\text { Cement concrete } \\
\text { Thermal insulation } \\
\text { layer }\end{array}$ & 2.56 & 1390 & 2480 \\
\hline
\end{tabular}

the cable, so as to improve the computational accuracy. The model is shown in Figure 15.

A series of temperature computations were conducted, respectively, with and without the heat-insulating layer. For instance, with the external temperature of $-5^{\circ} \mathrm{C}$ and $-10^{\circ} \mathrm{C}$, the model was heated for 5 hours and 10 hours, respectively, and the temperature distributions are shown in Figures 16 and 17.

From the temperature distribution, it can be seen that the temperature field formed among neighboring heating cables has "saddle shape" characteristic after a period of time. For the structural layer, the highest temperature appeared on the outer surface of heating cable. In the layer where the heating cable was installed, the temperature gradient was large. In the layer close to the road surface, the temperature gradient was small. And the temperature field on road surface was distributed uniformly. The simulation results were in good agreement with the research conducted by Yehia and Tuan [14].

Furthermore, considering that the external temperature of $-5^{\circ} \mathrm{C}$ and $-10^{\circ} \mathrm{C}$ and the heating time of $5 \mathrm{~h}$ and $10 \mathrm{~h}$ were adopted both for laboratory experiment and numerical investigation, we performed the related comparison and analysis, as shown in Figure 18. The pavement temperature changes in numerical investigation were basically closed to that in laboratory experiment. Additionally, the errors, which were reduced by the slight fluctuation of air temperature, heat exchange, thermal resistance between heating cable and pavement structure, and heterogeneity of materials, were
TABLE 4: Optimal preheating time without thermal insulation layer.

\begin{tabular}{lccc}
\hline $\begin{array}{l}\text { Air temperature } \\
\left({ }^{\circ} \mathrm{C}\right)\end{array}$ & $\begin{array}{c}\text { Target } \\
\text { temperature } \\
\left({ }^{\circ} \mathrm{C}\right)\end{array}$ & $\begin{array}{c}\text { Heating power } \\
\left(\mathrm{W} / \mathrm{m}^{2}\right)\end{array}$ & $\begin{array}{c}\text { Heating time } \\
(\mathrm{h})\end{array}$ \\
\hline-5 & 2 & 250 & 4.33 \\
-10 & 2 & 350 & 4.83 \\
-15 & 2 & 450 & 5.25 \\
-20 & 2 & 600 & 4.83 \\
\hline
\end{tabular}

TABLE 5: Optimal preheating time with thermal insulation layer.

\begin{tabular}{lccc}
\hline $\begin{array}{l}\text { Air temperature } \\
\left({ }^{\circ} \mathrm{C}\right)\end{array}$ & $\begin{array}{c}\text { Target } \\
\text { temperature } \\
\left({ }^{\circ} \mathrm{C}\right)\end{array}$ & $\begin{array}{c}\text { Heating power } \\
\left(\mathrm{W} / \mathrm{m}^{2}\right)\end{array}$ & $\begin{array}{c}\text { Heating } \\
\text { time }(\mathrm{h})\end{array}$ \\
\hline-5 & 2 & 200 & 4 \\
-10 & 2 & 250 & 5.5 \\
-15 & 2 & 300 & 5.5 \\
-20 & 2 & 400 & 5.5 \\
\hline
\end{tabular}

controlled within the relatively smaller range and would not affect the rationality of model.

Afterwards, further numerical simulation was conducted, and simulation results are shown in Tables 4 and 5. With the help of systematic numerical simulation, it was feasible to conduct the qualitative analysis of heating effects. Moreover, quantitative computation of the heating power and preheating time was also performed, which could provide technical support for similar projects in the future.

Based on the research results of field experiment, laboratory experiment, and numerical investigation, it is possible to conclude that the snow and ice on pavement can be melted very well with perfect economical performance by preheating the pavement to $2-3^{\circ} \mathrm{C}$ within $4-6 \mathrm{~h}$ with different air temperature and corresponding heating power. With air temperature dropping, the preheating time increases accordingly under the condition of the same heating power. In order to melt the snow and ice within reasonable preheating time, it is required to increase the heating power when the air temperature drops. Besides, considering the high utilization efficiency of heat, thermal insulation materials can be laid below the heating cables, so as to prevent the downward diffusion of heat and ensure that the heat can be transferred towards the surface layer of road. For the structural layer, the highest temperature appears on the outer surface of heating cable, and the lowest temperature appears on the upper surface of the layer. The pavement temperature changes in numerical investigation are in good agreement with that in laboratory experiment, and the related errors are controlled within the relatively smaller range. Therefore, it can be ascertained that the model established is rational and reliable, and simulation results have high reference values.

\section{Conclusions}

Considering the limitations of present antiskid measures adopted by highway maintenance division and the extensive 


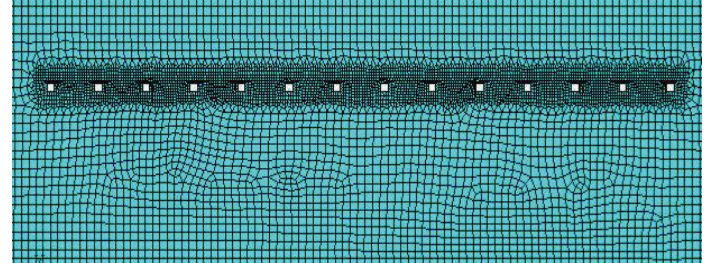

(a) Calculation model of the pavement without thermal insulation layer

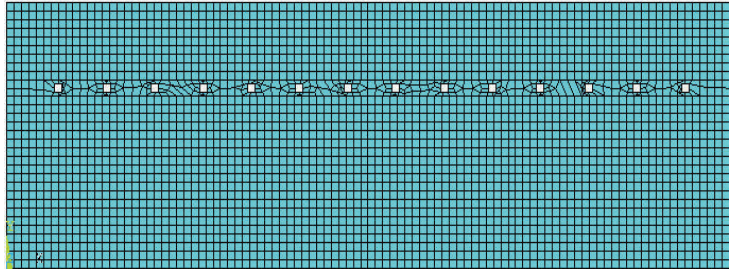

(b) Calculation model of the pavement with thermal insulation layer

Figure 15: Calculation model of the pavement.

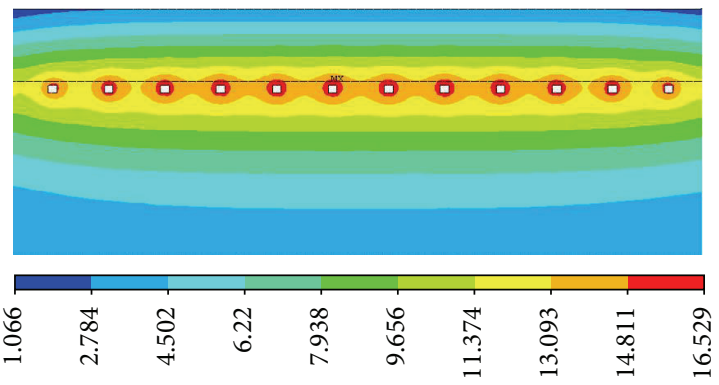

(a) Heating effect without thermal insulation layer

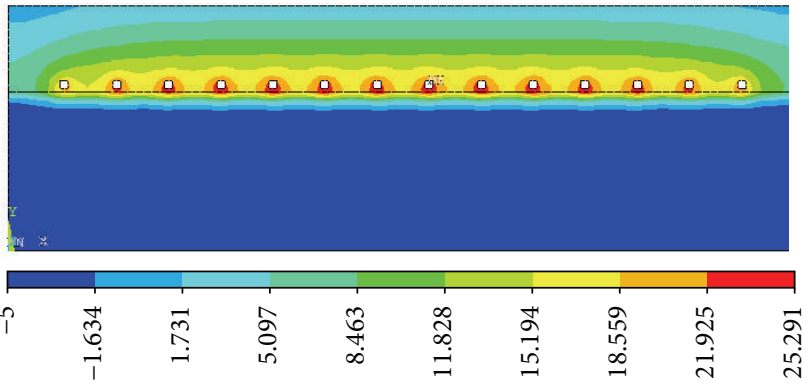

(b) Heating effect with thermal insulation layer

FIGURE 16: Temperature field distributions with heating time of 5 hours and air temperature of $-5^{\circ} \mathrm{C}$.
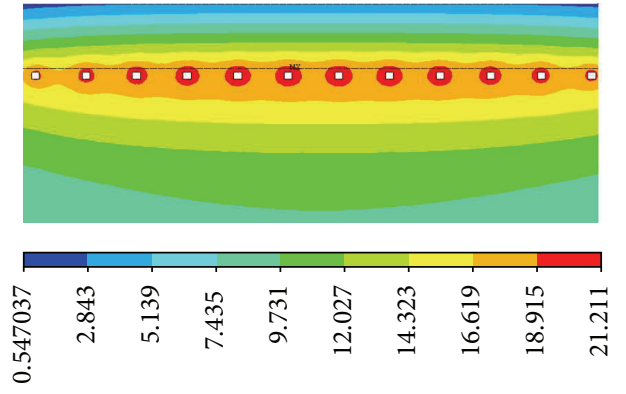

(a) Heating effect without thermal insulation layer
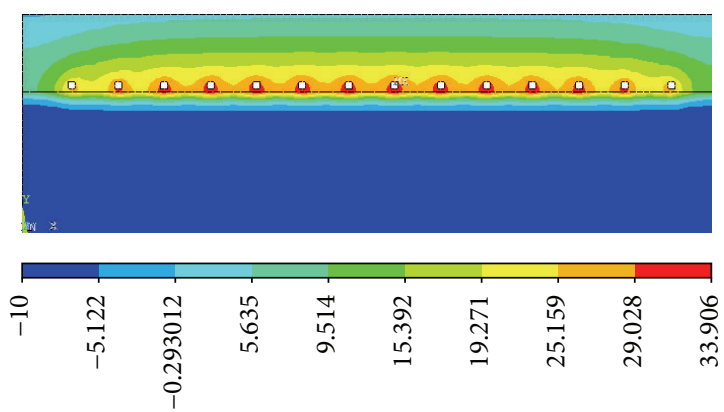

(b) Heating effect with thermal insulation layer

FIgURE 17: Temperature field distributions with heating time of 10 hours and air temperature of $-10^{\circ} \mathrm{C}$.

engineering applications of electric heat tracing system, the snow-melting heated pavement system in tunnel portal was proposed. Based on field experiment, laboratory experiment, and numerical investigation, conclusions may be summarized as follows:

(1) In cold region, the electric heat tracing system can be employed for the snow-melting of the pavement in tunnel portal. In order to realize instant and automatic melting, it is required to preheat the pavement according to the actual weather conditions.

(2) Considering the air temperature, vehicle emergency braking distance, and "snow scarp" effect, the optimum longitudinal length of the pavement with electric heat tracing system should be $50 \mathrm{~m}$ inside the tunnel and $50 \mathrm{~m}$ outside the tunnel.
(3) In order to effectively improve the heating efficiency, thermal insulation materials can be laid below the heating cables. Combined with thermal insulation materials, the electric heat tracing system with heating power of $200-400 \mathrm{~W} / \mathrm{m}^{2}$ can sufficiently meet the requirements of pavement snow-melting when the air temperature is $-20-0^{\circ} \mathrm{C}$.

(4) Based on field experiment and laboratory experiment, the numerical investigation can systematically analyze the temperature field distribution of the snowmelting heated pavement system, which truthfully reflects the temperature distribution of the pavement structure.

(5) The pavement heating power, heating time, and corresponding temperature distribution, which are 


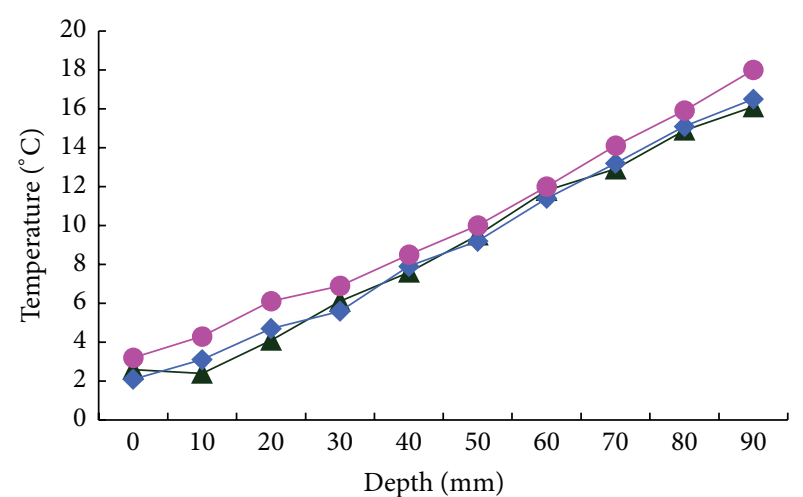

- Simulation results without thermal insulation layer $\rightarrow$ Test data

- Simulation results with thermal insulation layer

(a) Test data and simulation results with heating time of 5 hours

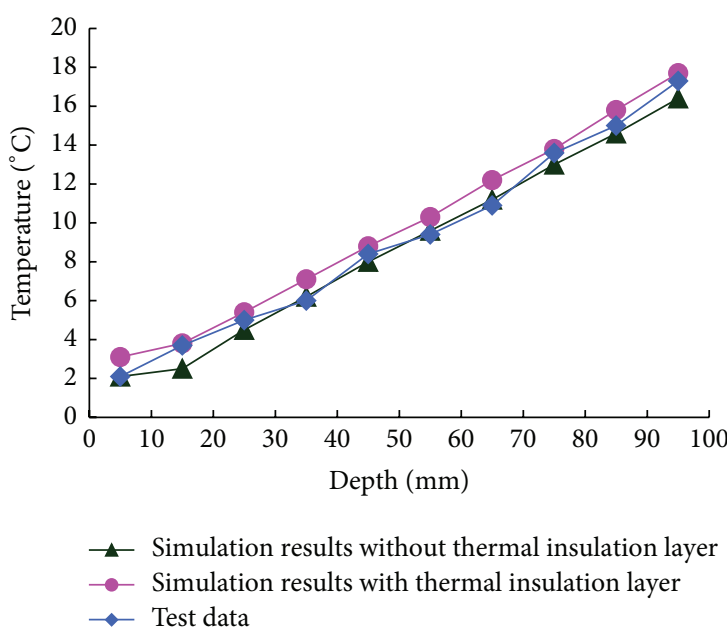

(b) Test data and simulation results with heating time of 10 hours

FIGURE 18: Comparison of the simulation results and test data.

obtained by the comprehensive comparison and analysis, not only offer technical support for the current research, but also lay foundation for the future research.

\section{Conflict of Interests}

The authors declare that there is no conflict of interests regarding the publication of this paper.

\section{Acknowledgments}

This work is financially supported by the Applied Basic Research Project (main subject) of the Ministry of Transport of China (no. 2015319812 140) and the Special Fund for Basic Scientific Research of Central Colleges of Chang'an University (Grant no. CHD2012JC072). The authors would like to express appreciation to the reviewers for their valuable comments and suggestions that helped to improve the quality of the paper.

\section{References}

[1] Z. Giergiczny, M. A. Glinicki, M. Sokołowski, and M. Zielinski, "Air void system and frost-salt scaling of concrete containing slag-blended cement," Construction and Building Materials, vol. 23, no. 6, pp. 2451-2456, 2009.

[2] M. S. Ialam, T. Fukuhara, and H. Watanabe, "Horizontal U-tube road heating system using tunnel ground heat," Journal of Snow Engineering of Japan, vol. 22, no. 3, pp. 23-28, 2006.

[3] L. N. Hu, "Application of electric heating system in the tunnel," Shanxi Electronic Technology, no. 3, pp. 11-12, 2013.

[4] W. Y. Ren, "On application of electric heat tracing insulation in water fire-fighting system of road tunnels," Shanxi Architecture, vol. 39, no. 20, pp. 177-178, 2013.

[5] Y. G. Cao, S. Guo, and J. Chen, "The research on preventing tunnel freezing damages using heat pipe and ground source heat pump system," Railway Standard Design, vol. 58, no. 10, pp. 97101, 2014.

[6] J. Zhao, H. Wang, Z. Chen, and H. Qu, "Seasonal behavior of pavement in geothermal snow-melting system with solar energy storage," Transactions of Tianjin University, vol. 12, no. 5, pp. 319-324, 2006.

[7] C.-Y. Lee and S.-R. Wang, "Analysis of resistance characteristics of conductive concrete using press-electrode method," World Academy of Science, Engineering and Technology, vol. 72, pp. 9194, 2010.

[8] A. Fujimoto, R. A. Tokunaga, M. Kiriishi et al., "A road surface freezing model using heat, water and salt balance and its validation by field experiments," Cold Regions Science and Technology, vol. 106-107, pp. 1-10, 2014.

[9] N. Banthia, S. Djeridane, and M. Pigeon, "Electrical resistivity of carbon and steel micro-fiber reinforced cements," Cement and Concrete Research, vol. 22, no. 5, pp. 804-814, 1992.

[10] H. C. Deng, W. X. Ma, and B. D. Jing, "Technology of removing snow and ice on roads and its developing trend," Construction Machinery and Equipment, no. 12, pp. 47-50, 2005.

[11] H. J. Wang, J. Zhao, and Z. H. Chen, "Experimental investigation of ice and snow melting process on pavement utilizing geothermal tail water," Energy Conversion and Management, vol. 49, no. 6, pp. 1538-1546, 2008.

[12] H. Wang and Z. Chen, "Study of critical free-area ratio during the snow-melting process on pavement using low-temperature heating fluids," Energy Conversion and Management, vol. 50, no. 1, pp. 157-165, 2009.

[13] J. M. Wu, J. G. Liu, and F. Yang, "Three-phase composite conductive concrete for pavement deicing," Construction and Building Materials, vol. 75, pp. 129-135, 2015.

[14] S. Yehia and C. Y. Tuan, "Conductive concrete overlay for bridge deck deicing," ACI Materials Journal, vol. 96, no. 3, pp. 382-390, 1999.

[15] A. D. Chiasson, J. D. Spitler, S. J. Rees, and M. D. Smith, "A model for simulating the performance of a pavement heating system as a supplemental heat rejecter with closed-loop ground-source heat pump systems," Journal of Solar Energy Engineering, vol. 122, no. 4, pp. 183-191, 2000. 
[16] B. Jelisejevs, "Alternative methods of de-icing on highways," Motorways, vol. 3, pp. 31-34, 2001.

[17] X. Liu, S. J. Rees, and J. D. Spitler, "Modeling snow melting on heated pavement surfaces. Part II: experimental validation," Applied Thermal Engineering, vol. 27, no. 5-6, pp. 1125-1131, 2007.

[18] J. Zhang, D. K. Das, and R. Peterson, "Selection of effective and efficient snow removal and ice control technologies for coldregion bridges," Journal of Civil, Environmental, and Architectural Engineering, vol. 3, no. 1, pp. 1-14, 2009.

[19] Y. P. Gao, "The system of deicing and melting on road surface by the solar energy," The Foreign Road, vol. 17, no. 4, pp. 853-855, 1999.

[20] N. F. Hong, "Deicing salt's corrosion and durability of reinforced concrete," Architecture Technology, vol. 31, no. 2, pp. 102-104, 2000.

[21] S. J. Rees, J. D. Spitler, and X. Xiao, "Transient analysis of snowmelting system performance," ASHRAE Transaction, vol. 108, no. 2, pp. 406-423, 2002.

[22] D. Sanzo and S. J. Hecnar, "Effects of road de-icing salt ( $\mathrm{NaCl})$ on larval wood frogs (Rana sylvatica)," Environmental Pollution, vol. 140, no. 2, pp. 247-256, 2006.

[23] P. Z. Fu, "Research on deicing and melting snow on road surface in Beijing," Technology of City Planning, vol. 29, no. 4, pp. 54-59, 2001.

[24] O. Ruth, "The effects of de-icing in Helsinki urban streams, Southern Finland," Water Science and Technology, vol. 48, no. 9, pp. 33-43, 2003.

[25] H. Luo, L. B. Luo, and J. Zhang, "Affecting and strategies for environment of the solvent of snow melting," Environmental Monitoring in China, vol. 20, no. 1, pp. 55-57, 2004.

[26] H. J. Wang, L. B. Liu, and Z. H. Chen, "Experimental investigation of hydronic snow melting process on the inclined pavement," Cold Regions Science and Technology, vol. 63, no. 1-2, pp. 44-49, 2010.

[27] W. J. Xue, D. Wang, and L. B. Wang, "A review and perspective about pavement monitoring," International Journal of Pavement Research and Technology, vol. 5, no. 5, pp. 295-302, 2012.

[28] S. Yehia, C. Y. Tuan, and D. Ferdonetal, "Conductive concrete overlay for bridge deck deicing: mixture proportioning optimization and properties," ACI Materials Journal, vol. 97, no. 2, pp. 172-181, 2000.

[29] P. Xie and J. J. Beaudo, "Electrically conductive concrete and its application in deicing," in Proceedings of the 2nd CANM ET/AC I International Symposium on Advances in Concrete Technology, SP2154, pp. 399-417, American Concrete Institute, Farmington Hills, Mich, USA, 1995.

[30] P. Xie, P. Gu, and J. J. Beaudoin, "Electrical percolation phenomena in cement composites containing conductive fibres," Journal of Materials Science, vol. 31, no. 15, pp. 4093-4097, 1996.

[31] X. Sun, "Application of conductive concrete in grounding grid in substation," High Voltage Engineering, vol. 27, no. 104, pp. 6667, 2001.

[32] Z. Tang, Z. Li, Z. Hou, and D. Xu, "Influence of setting of electrical conductive concrete heating layer on effectiveness of deicing," Journal of Wuhan University of Technology, vol. 24, no. 2, pp. 45-48, 2002.

[33] W. G. Qiao, D. Y. Li, and X. Z. Wu, "Survey analysis of freezing method applied to connected aisle in metro tunnel," Rock and Soil Mechanics, vol. 24, no. 4, pp. 2666-2669, 2003.

[34] Y.-F. Li, H.-Q. Wu, G.-M. Wang, B. Zhu, and B.-W. Shi, "Experimental study on the electrical road heating system for snow melting," Journal of Beijing University of Technology, vol. 32, no. 3, pp. 217-222, 2006.

[35] J. W. Ramsey and M. J. Hewett, "Updated design guidelines for snow-melting systems," ASHRAE Transactions, vol. 105, no. 2, pp. 1055-1065, 1999.

[36] I. B. Kilkis, "Design of embedded snow-melting system: part 1 , heat requirements-an overall assessment and recommendations," ASHRAE Transactions, vol. 100, no. 1, pp. 423-433, 1994.

[37] G. Xu, Research on Ice and Snow Removing Technique on Pavement Surface through Built-In Electric Heating, Harbin Institute of Technology, 2013.

[38] Y.-F. Li, S.-Y. Hu, H.-Q. Wu, J.-M. Li, and L.-S. Hou, "Modeling and analyzing on the electric system for deicing and melting snow on heating cable road surface," Journal of Beijing University of Technology, vol. 34, no. 12, pp. 1298-1303, 2008.

[39] H. M. Zhao, Z. M. Wu, S. G. Wang, J. Zheng, and G. Che, "Concrete pavement deicing with carbon fiber heating wires," Cold Regions Science and Technology, vol. 65, no. 3, pp. 413-420, 2011. 

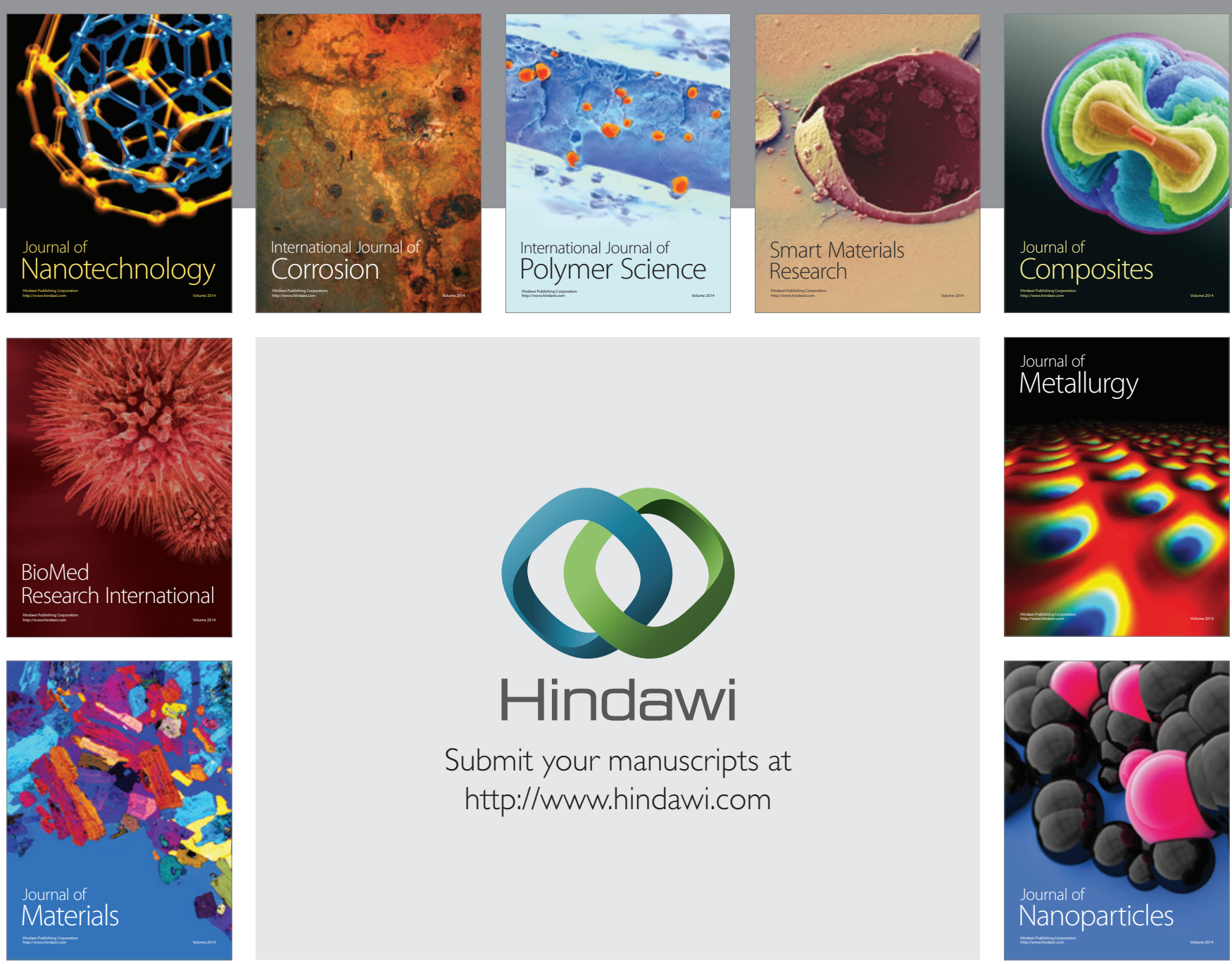

Submit your manuscripts at http://www.hindawi.com
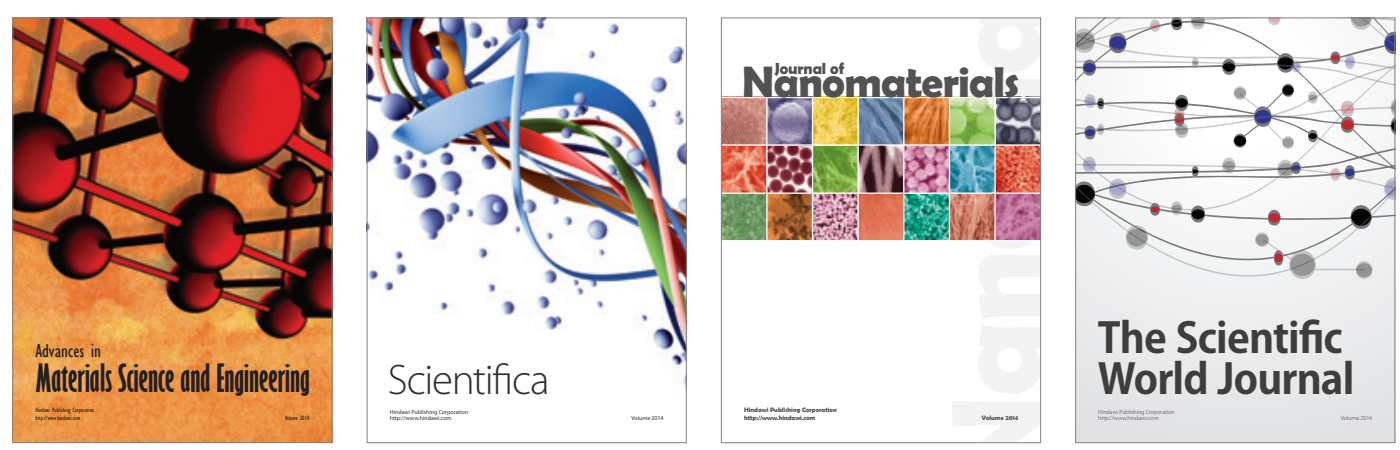

\section{The Scientific World Journal}
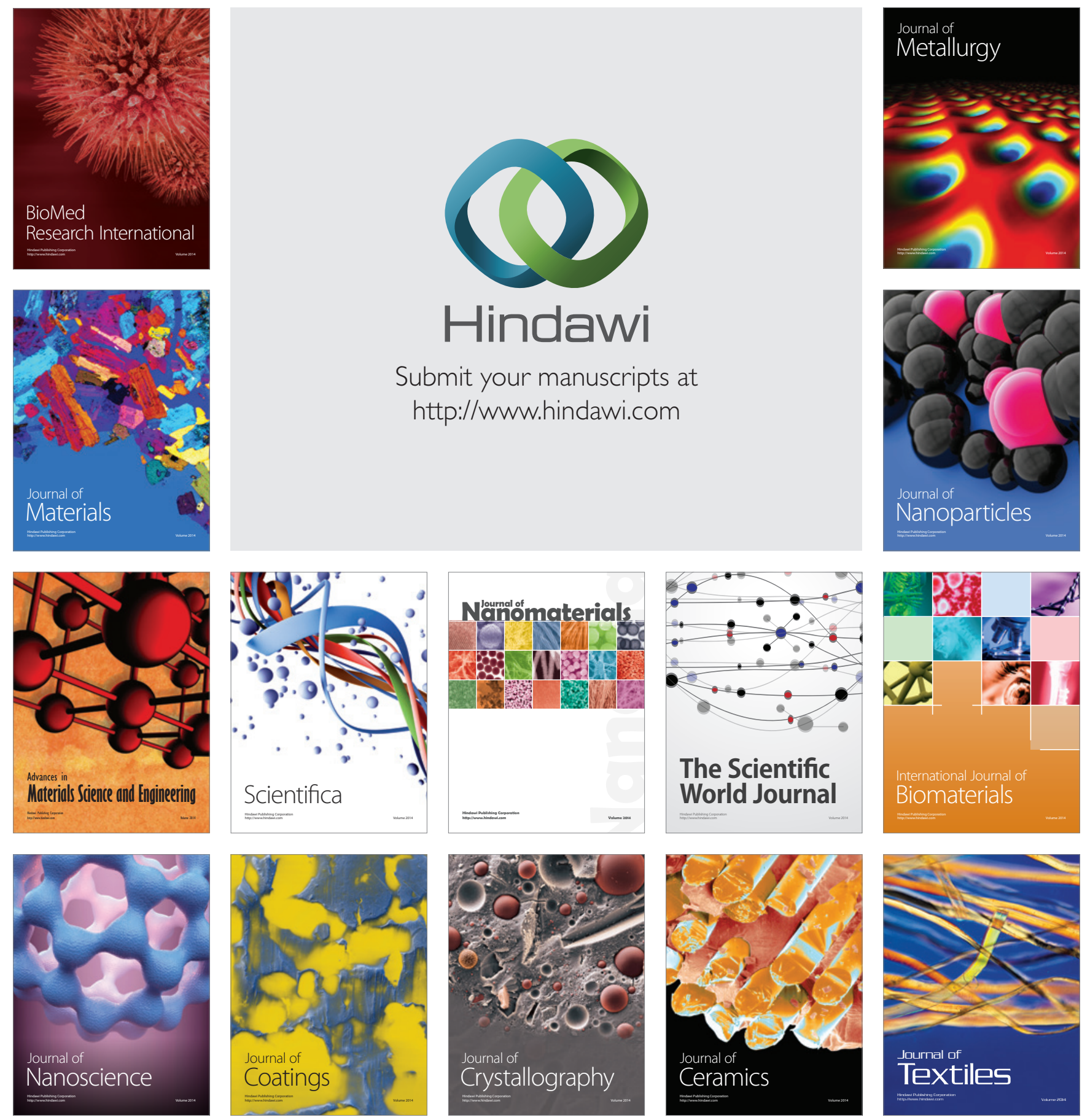